Molecules 2005, 10, 265-273

\title{
molecules
}

ISSN 1420-3049

http://www.mdpi.org

\section{Synthesis of Unsymmetrical Annulated 2,2'-Bipyridine Analogues with Attached Cycloalkene and Piperidine Rings via Sequential Diels-Alder Reaction of 5,5'-bi-1,2,4-triazines ${ }^{\dagger}$}

\section{Branowska *}

Institute of Chemistry, University of Podlasie, ul. 3 Maja 54, PL-08-110 Siedlce, Poland; Fax:(+48) 25644-2045

* Author to whom correspondence should be addressed; e-mail: dankab@ap.siedlce.pl

† Part 28 in "1,2,4-Triazines in Organic Synthesis". For part 27 see [1]

Received: 5 September 2004 / Accepted: 22 September 2004 / Published: 31 January 2005

\begin{abstract}
Synthesis of bisfunctionalized unsymmetrical 2,2'-bipyridines 8 or their sulfonyl derivatives 12a,b are described. They were prepared via the Diels-Alder reaction of 1-methyl-4-pyrrolidin-1-yl-1,2,3,6-tetrahydropyridine (6) with 3,3'-bis(methylsulfanyl)-5,5'-bi-1,2,4-triazine (1). The reaction leads to the single cycloaddition product 7 which undergoes Diels-Alder reaction with cyclic enamines $\mathbf{2 a , b}$ to give unsymmetrical 2,2'-bipyridine derivatives $\mathbf{8}$, consisting of the two different heterocyclic units: cycloalkeno[c]pyridine and 2,6-naphthyridine.
\end{abstract}

Keywords: bi-1,2,4-Triazines, Diels-Alder reaction, isocyclic and heterocyclic enamines

\section{Introduction}

Functionalized 2,2'-bipyridines have a wide range of applications in many areas of chemistry [2]. Especially interesting and useful are their annulated derivatives with benzo fusion incorporated into larger macropolycyclic structures, since they form stable luminescent complexes with a variety of lanthanide cations [3]. The transition metal complexes of chiral cycloalkenobipyridines have recently been employed as catalysts in a number of asymmetric reactions such as asymmetric cyclopropanation of alkenes [4], asymmetric alkylation of aldehydes [5], asymmetric hydrogenation and hydrosilylation [6] and asymmetric palladium catalysed allylic alkylation [7]. Although, there are several methods to synthesize annulated bipyridines with benzo fusion [8] only a limited number of reports have appeared regarding their analogues with saturated rings attached. The preparation of these ligands often rely on 
the transition-metal mediated heteroaryl cross-coupling reactions of specially prepared pyridines [9] or on the Kröhnke-type synthesis starting from $\alpha, \beta$-unsaturated ketones [10]. More recent approaches employ cobalt (I) catalysed [2+2+2] cycloadditions between 5-hexenenitrile and 1,3-diynes [11] or the double intramolecular Diels-Alder reactions of $\alpha, \beta$-unsaturated hydrazones with 1,3-dialkynes [12]. Alternatively, the construction of the fused pyridine ring can be achieved via intermolecular or intramolecular Diels-Alder (IDA) reactions of 1,2,4-triazines with inverse electron-demand [13]. We have applied this methodology to the direct synthesis of symmetrical and unsymmetrical annulated 2,2'-bipyridines 4 and 5 via the reaction of 5,5'-bi-1,2,4-triazine (1) with cyclic enamines 2a-d [14-16] (Scheme 1). This approach has been based on the regioselective, intermolecular [4+2] cycloaddition of $\mathbf{1}$ with cyclic enamines $\mathbf{2}$ to give a common intermediate $\mathbf{3}$. Subsequent treatment of the latter with the appropriate enamine leads to the annulated 2,2'-bipyridines 4 or 5 respectively.

\section{Scheme 1}

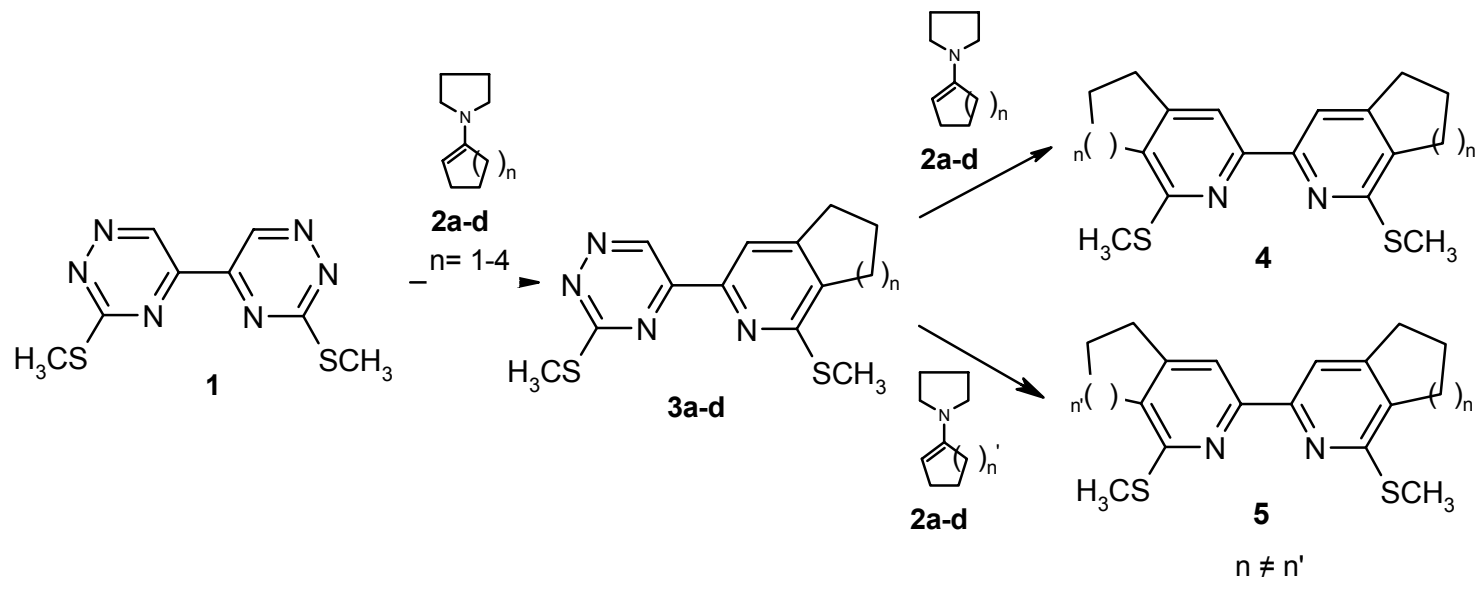

\section{Results and Discussion}

This paper describes the extension of the method to the synthesis of annulated 2,2'-bipyridine analogues 8, consisting of the two different heterocyclic units - 2,6-naphthyridine and cycloalkeno[c]pyridine (Scheme 2). The preparation of such compounds could involve the regiospecific conversion of the parent 3,3'-bis(methylsulfanyl)-5,5'-bi-1,2,4-triazine (1) to the single cycloaddition product $\mathbf{7}$ and the subsequent treatment of the latter with the cyclic enamine $\mathbf{2 a , b}$ (route a), or alternatively, the IDA reaction of the easily accessible $\mathbf{3 a}, \mathbf{b}$ with the appropriate dienophile $\mathbf{6}$ (route b).

Compound 7 was obtained via the single step [4+2]cycloaddition/retro cycloaddition reaction of easily available compound 1 [16] with 1-methyl-4-pyrrolidin-1-yl-1,2,3,6-tetrahydropyridine (6). The reaction was carried out with 1.5 molar excess of 6 in the boiling dioxane for $1 \mathrm{~h}$. The product 7 precipitated from the crude reaction mixture in $92 \%$ yield. In the reaction of 1 with 6 the formation of two isomeric 2,6- or 2,7-tetrahydronaphthyridine derivatives can be anticipated considering it involves the use of an unsymmetric enamine. However, the reaction gives only one reaction product in the excellent yield. Its ${ }^{1} \mathrm{H}-\mathrm{NMR}$ spectrum exhibited two signals of isolated aromatic protons at $\delta=9.97$ and $\delta=7.94 \mathrm{ppm}$ respectively. The former signal belongs to $1,2,4$-triazine and the latter one is attributed to 
the pyridine hydrogen. The separate signal of isolated methylene group appears at $\delta=3.65$, and the multiplet at $\delta=2.77$ can only corresponds to four vicinal hydrogens in saturated pyridine ring. Nuclear Overhauser Enhancement difference spectroscopy provided an unambigous assignment for this compound. It was found that irradiation of a proton in aromatic pyridine ring $(\delta=7.94 \mathrm{ppm})$ led to significant NOE for the signal of the isolated methylene group in the saturated pyridine ring $(\delta=3.65)$. These results and the lack of such interactions with the multiplet at $\delta=2.77$ provide evidence for spatial closeness of the pyridine hydrogen and $\mathrm{CH}_{2}$ and confirm the 2,6-tetrahydronaphthyridine derivative structure of 7 .

\section{Scheme 2}
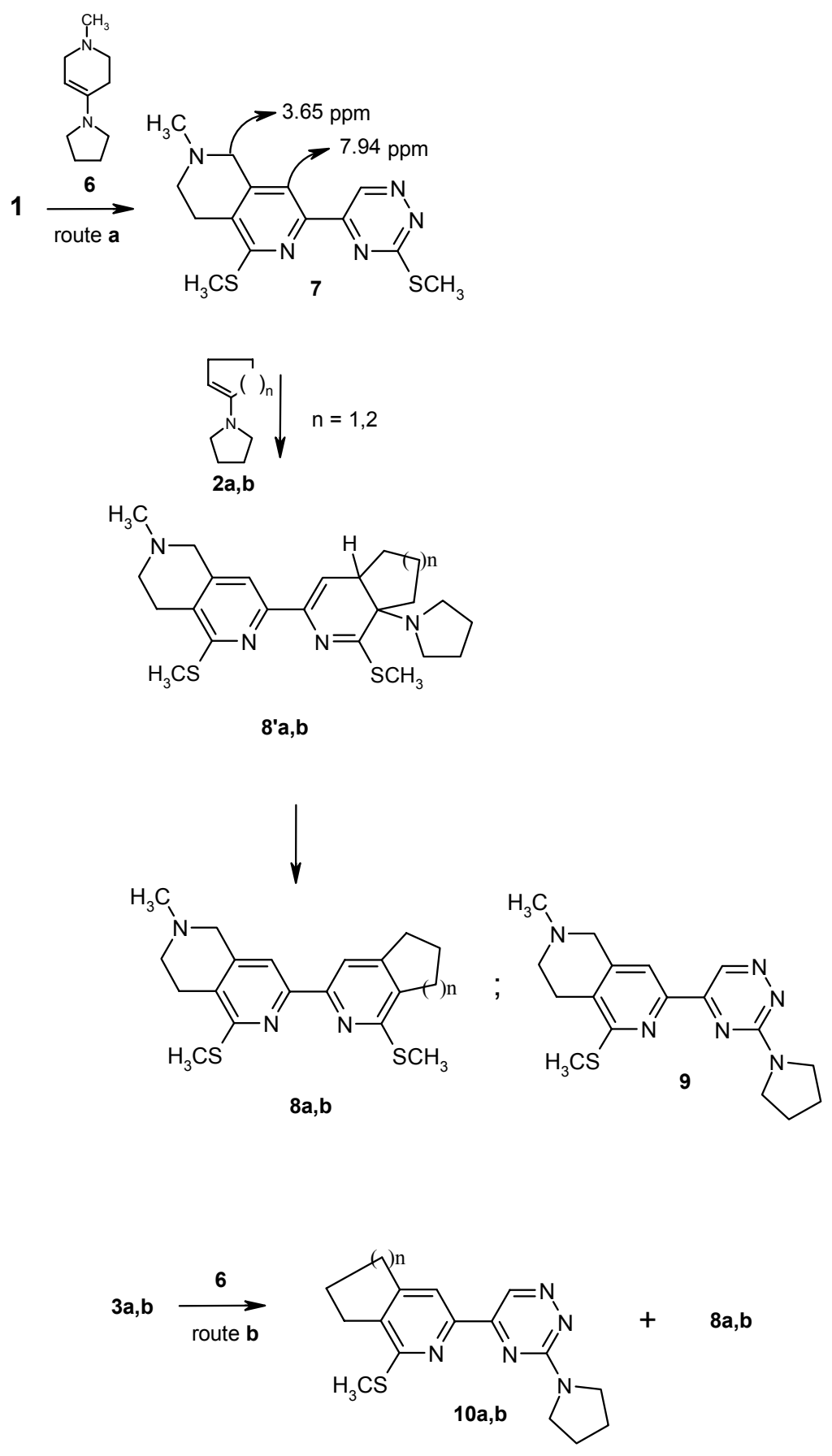
Heating 7 with an excess of 1-pyrrolidino-1-cyclopentene (2a, $\mathrm{n}=1)$ at $100{ }^{\circ} \mathrm{C}$ for 15 hours gives annulated 2,2'-bipyridine dihydroanalogue $\mathbf{8}$ 'a as a reaction intermediate. The latter is simply converted into 8a by heating with acetic acid in boiling toluene for 1 hour. Using less reactive 1-pyrrolidino-1-cyclohexene $(\mathbf{2} \mathbf{b}, \mathbf{n}=2)$ [11] and the similar reaction conditions, the annulated 2,2'bipiridine analogue $\mathbf{8 b}$ with a cyclohexene ring attached is prepared in low yield, while the corresponding pyrrolidino derivative $\mathbf{9}$ is obtained as a main product. This compound is also obtained by treatment of 3,3'-bis(methylsulfanyl)-5,5'-bi-1,2,4-triazine (1) with an excess of 6 without solvent at $100{ }^{\circ} \mathrm{C}$. Compound 9 is obviously formed by conventional nucleophilic replacement of methylsulfanyl group in 1,2,4-triazine part of 7. The single annulation products $\mathbf{3 a}(\mathrm{n}=1)$ and $\mathbf{3} \mathbf{b}(\mathrm{n}=2)$ undergo to small extent Diels-Alder reaction with 1-methyl-4-pyrrolidin-1-yl-1,2,3,6-tetrahydro-pyridine (6) to yield compounds $\mathbf{8 a}$ and $\mathbf{8 b}$ in low yield. Reaction of such derivatives has been found to result in a rather nucleophilic substitution of methylsulfonyl group in $\mathbf{3 a}$ and $\mathbf{3 b}$ giving compounds 10a and 10b respectively (Table 1). These results suggest that compound $\mathbf{6}$ is less reactive and less stable as a dienophile in comparison to cycloalkeno derived enamines $\mathbf{2 a}$ and $\mathbf{2 b}$.

Table 1. Yields of prepared compounds.

\begin{tabular}{clllllll}
\hline Entry & Reaction & $\mathbf{8 a}$ & $\mathbf{8} \mathbf{a}$ & $\mathbf{8 b}$ & $\mathbf{9}$ & $\mathbf{1 0 a}$ & $\mathbf{1 0 b}$ \\
\hline 1 & $\mathbf{7}+\mathbf{2 a}$ & $<1 \%$ & $60 \%$ & - & - & - & - \\
2 & $\mathbf{3 a}+\mathbf{6}$ & $23 \%$ & $8 \%$ & - & - & $30 \%$ & - \\
3 & $7+\mathbf{2 b}$ & - & - & $10 \%$ & $50 \%$ & - & - \\
4 & $\mathbf{3 b}+\mathbf{6}$ & - & - & $5 \%$ & - & - & $64 \%$ \\
5 & $\mathbf{1}+\mathbf{6}$ & - & - & - & $72 \%$ & - & - \\
6 & $\mathbf{8} \mathbf{a}+\mathbf{H O A c}$ & $98 \%$ & - & - & - & - & - \\
\hline
\end{tabular}

In order to help us better characterize the cycloaddition reactions of $\mathbf{3 a , b}$ with $\mathbf{6}$ as well as cyclic enamines $\mathbf{2 a}, \mathbf{b}$ with 7 , we calculated the energy differences $(\Delta \mathrm{E})$ between the LUMO of diene and HOMO of dienophile, using the AM1 semiempirical method [17]. The results are presented in Table 2. A better orbital overlap should be obtained between the HOMO orbital of cyclic enamines $\mathbf{2 a}, \mathbf{b}$ and the LUMO orbital of the 7 than in combination of 1-methyl-4-pyrrolidin-1-yl-1,2,3,6-tetrahydropyridine 6 with 3a,b because the energy gaps are smaller and range from 0.02 to $0.05 \mathrm{eV}$.

Table 2. Energy Values of the HOMO of Dienophiles Calculated by the AM1 Semiempirical method, and $\mathrm{LUMO}_{\text {diene }}-\mathrm{HOMO}_{\text {dienophile }}$ Energy Differences $(\Delta \mathrm{E})$

\begin{tabular}{|c|c|c|c|}
\hline Dienophile $\mathbf{E}_{\text {номо }}(\mathrm{eV})$ & Comp. & & $\Delta \mathbf{E}$ \\
\hline $6:-8.2212$ & & ( $\mathrm{E}_{\text {LUMO diene } \mathbf{7 a}-} \mathrm{E}_{\text {HOMO dienophile 2a,b) }}$ ) & $\left(\mathrm{E}_{\text {LUMO diene } \mathbf{3 a , b}-\mathbf{b}} \mathrm{E}_{\mathrm{HOMO} \text { dienophile } \mathbf{6}}\right)$ \\
\hline 2a: -8.0790 & $\mathbf{8 a}$ & 7.1193 & 7.1491 \\
\hline 2b: -8.0823 & $8 \mathbf{b}$ & 7.1226 & 7.1740 \\
\hline
\end{tabular}


From the above data it is clear that compounds $\mathbf{3 a} \mathbf{a}, \mathbf{b}$ are not suitable intermediates for the synthesis of bipyridine derivatives $\mathbf{8 a}, \mathbf{b}$. It is well known however that introduction of electron-withdrawing substiuents increases deficiency in the 1,2,4-triazine ring and enhances its reactivity in Diels-Alder reaction [12]. We have therefore explored the reaction between $\mathbf{6}$ and methylsulfonyl derivatives 11a,b, easily available by oxidation of $\mathbf{3 a , b}$ with $\mathrm{KMnO}_{4}$ under phase transfer catalysis conditions [18] (Scheme 3). The reaction of $\mathbf{1 1 a , b}$ with heterocyclic enamine $\mathbf{6}$ is complete within 1 hour at room temperature leading to unsymmetrical annulated 2,2'-bipyridine analogues 12a and 12b in good yield (Scheme 3).

\section{Scheme 3}

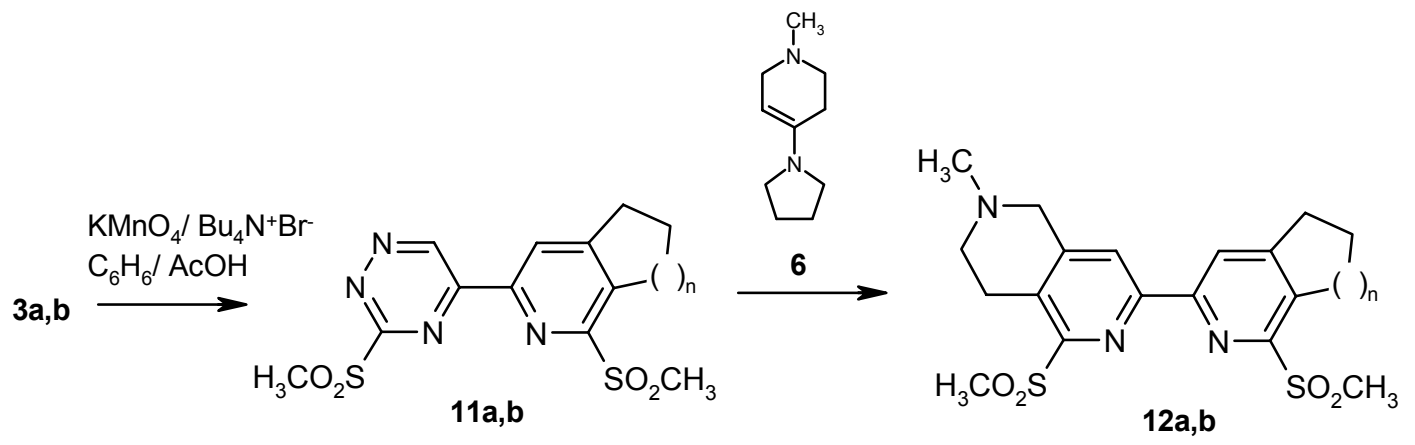

\section{Conclusions}

In summary, we have developed a new route to unsymmetrical annulated 2,2'-bipyridine analogues with cycloalkene and piperidine rings attached bearing alkylsulfanyl and alkylsulfonyl groups in both pyridine rings. The presence of such leaving groups makes these compounds attractive as building blocks for the synthesis of macrocycles.

\section{Acknowledgments}

The author is grateful to Prof. Andrzej Rykowski of the University of Podlasie for fruitful discussions and to Dr. Zbigniew Karczmarzyk for the calculations using the AM1 semiempirical method.

\section{Experimental}

\section{General}

Melting points are uncorrected. IR spectra were measured with a Magna IR-760 spectrophotometer. The ${ }^{1} \mathrm{H}-\mathrm{NMR}$ spectra were recorded in deuteriochloroform on a Varian-Gemini $200 \mathrm{MHz}$ spectrometer. Mass spectra were measured with an AMD 604 (AMD Intectra GmbH, Germany). Column chromatography was performed on silica gel (230-400 mesh, 60 Merck). All solvents used were dried and distilled according to standard procedures [21]. Merck $60 \mathrm{~F}_{254}$ plates were used for analytical (TLC) chromatography. 3-Methylsulfanyl-1,2,4-triazine (1)[22], 1-methyl-sulfonyl-3-(3-methylsulfonyl-1,2,4triazin-5-yl)-6,7-dihydro-5H-cyclopenta[c]pyridine (11a) and 1-methylsulfonyl-3-(3-methyl-sulfonyl- 
1,2,4-triazin-5-yl)-5,6,7,8-tetrahydroisioquinoline (11b)[20], 1-methyl-4-pyrrolidin-1-yl-1,2,3,4-tetrahydropyridine (6) and 1-pyrrolidino-1-cyclopentene (2a) and 1-pyrrolidino-1-cyclohexene (2b) [23] were prepared according to literature methods. Naphthyridine derivatives $\mathbf{8 a}, \mathbf{b}$ and $\mathbf{1 2 a} \mathbf{a}, \mathbf{b}$ are air sensitive and decompose upon standing.

2-Methyl-5-methylsulfanyl-7-(3-methylsulfanyl-1,2,4-triazin-5-yl)-1,2,3,4-tetrahydro-2,6-naphthyridine (7): A solution of 1 (1.25 g, $4.96 \mathrm{mmol})$ and 1-methyl-4-pyrrolidin-1-yl-1,2,3,6-tetrahydropyridine (6, $1.2 \mathrm{~g}, 7.23 \mathrm{mmol})$ in dry dioxane $(20 \mathrm{~mL})$ was refluxed for $1 \mathrm{~h}$. The solvent was evaporated under reduced pressure and the residue was recrystallized from ethanol-water to give $1.4 \mathrm{~g}(92 \%)$ of 7 as an orange solid. M. p. $205-206{ }^{\circ} \mathrm{C}$; IR (KBr) $\gamma \mathrm{cm}^{-1} 1165,1440,1540,2800,2960 ;{ }^{1} \mathrm{H}-\mathrm{NMR} \delta: 2.42$ (s, 3H), 2.60-2.90 (m, 4H), 2.65 (s, 3H), 2.80 (s, 3H), 3.65 (s, 2H), 7.94 (s, 1H), 9.97 (s, 1H); HRMS (EI): $m / z$ calc. for $\mathrm{C}_{14} \mathrm{H}_{17} \mathrm{~N}_{5} \mathrm{~S}_{2}\left(\mathrm{M}^{+}\right): 319.09253$, found 319.09604 .

2-Methyl-5-methylsulfanyl-7-(3-pyrrolidin-1-yl-1,2,4-triazin-5-yl)-1,2,3,4-tetrahydro-2,6-naphthyridine (9): A mixture of 3,3'-bis(methylsulfanyl)-5,5'-bi-1,2,4-triazine (1, $0.50 \mathrm{~g}, 1.98 \mathrm{mmol})$ and 1-methyl-4pyrrolidin-1-yl-1,2,3,6-tetrahydropyridine $(6,3 \mathrm{~mL})$ was heated at $100{ }^{\circ} \mathrm{C}$ for $16 \mathrm{~h}$. After cooling the mixture was purified by column chromatography using first chloroform and next chloroform-acetone (50:1) to give $0.69 \mathrm{~g}(72 \%)$ of 9 as a yellow solid. M. p. $205-206{ }^{\circ} \mathrm{C}$; IR (KBr) $\gamma \mathrm{cm}^{-1} 1251,1485$, 1538, 2873, 2942; ${ }^{1} \mathrm{H}-\mathrm{NMR} \delta$ : 2.03-2.07 (m, 4H), 2.47 (s, 3H), 2.66 (s, 3H), 2.76 (s, 4H), 3.60 (s, 2H), 3.74 (broad s, $4 \mathrm{H}), 7.84(\mathrm{~s}, 1 \mathrm{H}), 9.54(\mathrm{~s}, 1 \mathrm{H})$; HRMS (EI): $m / z$ calc for $\mathrm{C}_{17} \mathrm{H}_{22} \mathrm{~N}_{6} \mathrm{~S}\left(\mathrm{M}^{+}\right)$: 342.16267 , found 342.16317 .

2-Methyl-5-methylsulfanyl-7-(1-methylsulfanyl-6,7-dihydro-5H-cyclopenta[c]pyridin-3-yl)-1,2,3,4tetrahydro-2,6-naphthyridine (8a) and 2-methyl-5-methylsulfanyl-7-(1-methylsulfanyl-7a-pyrrolidin-1yl-5,6, 7,7a-tetrahydro-4aH-cyclopenta[c]pyridin-3-yl)-1,2,3,4-tetrahydro-2,6-naphthyridine (8'a):

The synthesis of compound $\mathbf{8 a}$ was accomplished by two different routes ( $\mathbf{a}$ and $\mathbf{b}$, respectively):

Route a: A mixture of $7(0.36 \mathrm{~g}, 1.18 \mathrm{mmol})$ and $\mathbf{2 a}(2.5 \mathrm{~mL})$ was heated at $100{ }^{\circ} \mathrm{C}$ for $16 \mathrm{~h}$. After cooling the mixture was purified by column chromatography using first chloroform and next chloroform-acetone $(50: 1)$ to give $\mathbf{8 a}$ and $\mathbf{8}$ 'a $(0.30 \mathrm{~g}, 60 \%)$. The mixture of the crude dihydro derivative $\mathbf{8}$ 'a $(0.20 \mathrm{~g}, 0.47 \mathrm{mmol})$, toluene $(10 \mathrm{~mL})$ and HOAc $(1 \mathrm{~mL})$ was refluxed for $1 \mathrm{~h}$. After cooling the precipitated solid was filtered off and recrystallized from ethanol to give $0.16 \mathrm{~g}(98 \%)$ of 8a as a yellow solid.

8a: M. p. 209-211 ${ }^{\circ} \mathrm{C}$; IR (KBr) $\gamma \mathrm{cm}^{-1} 1200,1404,1576,2766,2945 ;{ }^{1} \mathrm{H}-\mathrm{NMR} \delta: 2.17$ (qui, $2 \mathrm{H}, J=7.4$ $\mathrm{Hz}), 2.48(\mathrm{~s}, 3 \mathrm{H}), 2.70(\mathrm{~s}, 6 \mathrm{H}), 2.78(\mathrm{~s}, 4 \mathrm{H}), 2.83(\mathrm{t}, 2 \mathrm{H}, J=7.5 \mathrm{~Hz}), 3.02$ (t, 2H, J=7.5 Hz), 3.62 (s, $2 \mathrm{H}), 7.84(\mathrm{~s}, 1 \mathrm{H}), 8.06(\mathrm{~s}, 1 \mathrm{H})$; HRMS (EI): $m / z$ calc for $\mathrm{C}_{19} \mathrm{H}_{23} \mathrm{~N}_{3} \mathrm{~S}_{2}\left(\mathrm{M}^{+}\right)$: 357.13334, found 357.13433.

8'a: M. p. $170-171{ }^{\circ} \mathrm{C}$; IR (KBr) $\gamma \mathrm{cm}^{-1} 1240,1303,1575,2803,2947 ;{ }^{1} \mathrm{H}-\mathrm{NMR} \delta: 1.54-1.60$ (m, 2H), 1.66-1.71 (m, 5H), 2.09-2.35 (m, 4H), $2.45(\mathrm{~s}, 3 \mathrm{H}), 2.49$ (s, 4H), $2.62(\mathrm{~s}, 3 \mathrm{H}), 2.51-2.75(\mathrm{~m}, 4 \mathrm{H}), 2.72$ 
(m, 3H), $3.55(\mathrm{~s}, 2 \mathrm{H}), 6.91(\mathrm{~d}, 1 \mathrm{H}, J=6.1 \mathrm{~Hz}), 7.51(\mathrm{~s}, 1 \mathrm{H})$; HRMS (EI): $m / z$ calc for $\mathrm{C}_{23} \mathrm{H}_{32} \mathrm{~N}_{4} \mathrm{~S}_{2}\left(\mathrm{M}^{+}\right)$: 428.20684, found 428.20728 .

Route b: A mixture of 3a $(0.26 \mathrm{~g}, 0.89 \mathrm{mmol})$ and $\mathbf{6}(2 \mathrm{~mL})$ was heated at $100{ }^{\circ} \mathrm{C}$ for $16 \mathrm{~h}$. After cooling the mixture was purified by column chromatography using chloroform and next chloroform: acetone (50:1) to give $\mathbf{8 a}(0.08 \mathrm{~g}, 23 \%)$ and 1-methylsulfanyl-3-(3-pyrrolidin-1-yl-1,2,4-triazin-5-yl)6,7-dihydro-5H-cyclopenta[c]pyridine (10a, 0.085 g, $30 \%$ ). M. p. 220-221 ${ }^{\circ} \mathrm{C}$; IR (KBr) $\gamma \mathrm{cm}^{-1} 1289$, 1396, 1534, 2870, 2942; ${ }^{1} \mathrm{H}-\mathrm{NMR} \delta: 2.0-2.1$ (m, 4H), 2.09 (qui, 2H, J=7.4 Hz), 2.68 (s, 3H), 2.88 (t, $2 \mathrm{H}, J=6.1 \mathrm{~Hz}), 2.98$ (t, 2H, $J=6.0 \mathrm{~Hz}), 3.74$ (broad s, 4H), 8.05 (s, 1H), 9.54 (s, 1H); HRMS (EI): $m / z$ calc for $\mathrm{C}_{16} \mathrm{H}_{20} \mathrm{~N}_{5} \mathrm{~S}(\mathrm{M}+\mathrm{H})$ calculated 314.1434 found 314.1443.

2-Methyl-5-methylsulfanyl-7-(1-methylsulfanyl-5, 6, 7,8-tetrahydroisoquinolin-3-yl)-1,2,3,4-tetrahydro-

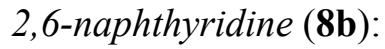

The synthesis of compound $\mathbf{8 b}$ has been accomplished by two different routes ( $\mathbf{a}$ or $\mathbf{b})$.

Route a: A mixture of $7(0.36 \mathrm{~g}, 1.18 \mathrm{mmol})$ and $\mathbf{2 b}(2.5 \mathrm{~mL})$ was heated at $100{ }^{\circ} \mathrm{C}$ for $16 \mathrm{~h}$. After cooling the mixture was purified by column chromatography using first chloroform and next chloroform-acetone (50:1) to give $\mathbf{8 b}(0.042 \mathrm{~g}, 10 \%)$ and $\mathbf{9}(0.19 \mathrm{~g}, 50 \%)$.

8b: M. p. $210-212{ }^{\circ} \mathrm{C}$; IR (KBr) $\gamma \mathrm{cm}^{-1} 1292,1377,1573,2766,2947 ;{ }^{1} \mathrm{H}-\mathrm{NMR} \delta: 1.78-1.90$ (m, 4H), $2.48(\mathrm{~s}, 3 \mathrm{H}), 2.59-2.65(\mathrm{t}, 2 \mathrm{H}, J=6.1 \mathrm{~Hz}), 2.67(\mathrm{~s}, 3 \mathrm{H}), 2.69(\mathrm{~s}, 3 \mathrm{H}), 2.77(\mathrm{~s}, 4 \mathrm{H}), 2.80(\mathrm{t}, 2 \mathrm{H}, J=6.0 \mathrm{~Hz})$, $3.62(\mathrm{~s}, 2 \mathrm{H}), 7.83(\mathrm{~s}, 1 \mathrm{H}), 7.86(\mathrm{~s}, 1 \mathrm{H})$; HRMS (EI): $m / z$ calc for $\mathrm{C}_{20} \mathrm{H}_{25} \mathrm{~N}_{3} \mathrm{~S}_{2}\left(\mathrm{M}^{+}\right): 371.14899$, found 371.14830 .

Route b: A mixture of $\mathbf{3 b}(0.29 \mathrm{~g}, 0.95 \mathrm{mmol})$ and $\mathbf{6}(2 \mathrm{~mL})$ was heated at $100{ }^{\circ} \mathrm{C}$ for $32 \mathrm{~h}$. After cooling the mixture was purified by column chromatography using first chloroform and next chloroformacetone (50:1) to give $\mathbf{8 b}(0.001 \mathrm{~g}, 5 \%)$ and 1-methylsulfanyl-3-(3-pyrrolidin-1-yl-1,2,4-triazin-5-yl)5,6,7,8-tetrahydroisoquinoline (10b, 0.02 g, 64 \%). M. p. 131-132 ${ }^{\circ} \mathrm{C}$; IR (KBr) $\gamma \mathrm{cm}^{-1} 1289,1396$, 1534, 2870, 2942; ${ }^{1} \mathrm{H}-\mathrm{NMR} \delta:$ 1.79-1.92 (m, 4H), 2.03-2.17 (m, 4H), 2.62 (t, 2H, J=6.1 Hz), 2.66 (s, $3 \mathrm{H}), 2.80(\mathrm{t}, 2 \mathrm{H}, J=6.0 \mathrm{~Hz}), 3.75$ (broad s, 4H), $7.86(\mathrm{~s}, 1 \mathrm{H}), 9.55$ (s, 1H); HRMS (EI): $\mathrm{m} / z$ calc for $\mathrm{C}_{17} \mathrm{H}_{21} \mathrm{~N}_{5} \mathrm{~S}\left(\mathrm{M}^{+}\right)$: 327.15177, found 327.15139.

2-Methyl-5-methylsulfonyl-7-(1-methylsulfonyl-6,7-dihydro-5H-cyclopenta[c]pyridin-3-yl)-1,2,3,4tetrahydro-2,6-naphthyridine (12a): A mixture of 11a (1.24 g, $3.5 \mathrm{mmol})$ and 1-methyl-4-pyrrolidin-1yl-1,2,3,6-tetrahydro-pyridine $(6,1.16 \mathrm{~g}, 6.98 \mathrm{mmol})$ in dioxane $(16 \mathrm{~mL})$ was stirred at room temperature for $1 \mathrm{~h}$. The crude product was purified by column chromatography using chloroformacetone (10:1) as eluent, to give $0.83 \mathrm{~g}(56 \%)$ of 12a as a yellow solid. M. p. 199-200 ${ }^{\circ} \mathrm{C}$; IR (KBr) $\gamma$ $\mathrm{cm}^{-1}$ 1200, 1404, 1576, 2766, 2945; ${ }^{1} \mathrm{H}-\mathrm{NMR} \delta$ : 1.95-2.1 (m, 2H), 2.24 (qui, 2H, J=7.5 Hz), 2.49 (s, $3 \mathrm{H}), 2.77$ (t, 2H, $J=7.5 \mathrm{~Hz}), 3.07$ (t, 2H, $J=7.6 \mathrm{~Hz}), 3.37$ (s, 3H), 3.39-3.48 (m, 2H), $3.48(\mathrm{~s}, 3 \mathrm{H}), 3.73$ $(\mathrm{s}, 2 \mathrm{H}), 8.20(\mathrm{~s}, 1 \mathrm{H}), 8.32(\mathrm{~s}, 1 \mathrm{H})$; HRMS (LSIMS): $m / z$ calc for $\mathrm{C}_{19} \mathrm{H}_{24} \mathrm{O}_{4} \mathrm{~N}_{3} \mathrm{~S}_{2}(\mathrm{M}+\mathrm{H}): 422.12082$, found 422.12017 . 
2-Methyl-5-methylsulfonyl-7-(1-methylsulfonyl-5,6,7,8-tetrahydroisoquinolin-3-yl)-1,2,3,4-tetrahydro2,6-naphthyridine (12b): A mixture of $\mathbf{1 1 b}(0.56 \mathrm{mg}, 1.54 \mathrm{mmol})$ and 1-methyl-4-pyrrolidin-1-yl1,2,3,6-tetrahydro-pyridine $(6,0.52 \mathrm{~g}, 3.08 \mathrm{mmol})$ in dioxane $(16 \mathrm{~mL})$ was stirred at room temperature for $0.5 \mathrm{~h}$ under nitrogen. The solvent was evaporated under reduced pressure. The crude product was purified by column chromatography using chloroform-acetone $(10: 1)$ as eluent, to give $0.58 \mathrm{~g}(62 \%)$ of 12b as a yellow solid. M. p. $285-286{ }^{\circ} \mathrm{C}$; IR $(\mathrm{KBr}) \gamma \mathrm{cm}^{-1} 1128,1302,1586,2931,3011$; ${ }^{1} \mathrm{H}-\mathrm{NMR} \delta$ : 1.78-1.90 (m, 6H), $2.50(\mathrm{~s}, 3 \mathrm{H}), 2.78(\mathrm{t}, 2 \mathrm{H}, J=5.9 \mathrm{~Hz}), 2.90-3.00(\mathrm{~m}, 2 \mathrm{H}), 3.25-3.40(\mathrm{~m}, 2 \mathrm{H}), 3.48(\mathrm{~s}$, $6 \mathrm{H}), 3.76(\mathrm{~s}, 2 \mathrm{H}), 8.06(\mathrm{~s}, 1 \mathrm{H}), 8.10(\mathrm{~s}, 1 \mathrm{H})$; HRMS (LSIMS): $m / z$ calc for $\mathrm{C}_{20} \mathrm{H}_{26} \mathrm{O}_{4} \mathrm{~N}_{3} \mathrm{~S}_{2}(\mathrm{M}+\mathrm{H})$ : 436.13647, found 436.13755 .

\section{References and Notes}

1. Lipinska, T. Tetrahedron Lett. 2004, 45, 8831.

2. Kaes, C.; Katz, A.; Hosseini, M.W. Chem. Rev. 2000, 100, 3553.

3. a) Pietraszkiewicz, M.; Karpiuk, J.; Pietraszkiewicz, O. Spectrochim. Acta Part A 1998, 54, 2229 and references cited therein; b) Pietraszkiewicz, M. Comprehensive Supramolecular Chemistry; Lehn, J.-M.; Kaes, C.; Katz, A.; Hosseini, M. (Eds.) Luminescent Probes; Pergamon: Oxford, U.K. 1996, 10, 225.

4. a) Ito, K.; Yoshitake, M.; Katuski, T. Tetrahedron 1996, 52, 3905; b) Malkov, A.V.; Baxendale, I. R.; Bella, M.; Langer, V.; Fawcett, J.; Russell, D. R.; Mansfield, D. J.; Valko, M.; Kocovsky, P. Organometallics 2001, 20, 673; c) Lötscher, D.; Rupprecht, H.; Stoeckli-Evans, H.; von Zalewsky, A. Tetrahedron-Asymmetr. 2000, 11, 4341; d) Chelucci, G.; Gladiali, S.; Sanna, M. G.; Brunner, H. Tetrahedron-Asymmetr. 2000, 11, 3419.

5. Collomb, P.; von Zalewsky, A. Tetrahedron-Asymmetr. 1998, 9, 3911.

6. Gladiali, S.; Pinna, L.; Delogu, G.; Graf, E.; Brunner, H. Tetrahedron-Asymmetr. 1990, 1, 937.

7. a) Chelucci, G.; Pinna, G. A.; Saba, A. Tetrahedron-Asymmetr. 1998, 9, 531; b) Chelucci, G.; Saba, A.; Sanna, G.; Soccolini, F. Tetrahedron-Asymmetr. 2000, 11, 3427.

8. Steel, P. J. Adv. Heterocyclic Chem. 1997, 67, 1.

9. a) Ito, K.; Tabuchi, S.; Katuski, T. Synlett 1992, 575; b) Ito, K.; Katuski, T. Tetrahedron Lett. 1993, 34, 2661.

10. Hayoz, P.; von Zalewsky, A. Tetrahedron Lett. 1992, 33, 5165.

11. Varella, J. A.; Castedo, L.; Maestro, M.; Mahia, J.; Saci, C. Chem. Eur. J. 2001, 7, 5203.

12. Bushby, M.; Moody, C. J.; Riddick D. A.; Waldron, I. R., J. Chem. Soc., Perkin Trans.1 2001, 2183.

13. Rickborn, B. In Organic Reactions; Paquette L. A. (Ed.); J. Wiley and Sons: New York, 1998; 53, 493.

14. Rykowski, A.; Branowska, D.; Kielak, J. Tetrahedron Lett. 2000, 41, 3657.

15. Branowska, D. and Rykowski, A. Synlett, 2002, 1892.

16. Branowska, D. Synthesis, 2003, 2096.

17. Krass, D. K.; Chen, T.-K.; Paudler W. W. J. Heterocyclic Chem, 1973, 10, 343.

18. Rykowski, A.; Lipinska, T. Polish J. Chem. 1997, 71, 83.

19. Dewar, M. J. S.; Zoebisch, E. G.; Healy, E. F.; Stewart, J. J. P. J. Am. Chem. Soc. 1993, 115, 872.

20. Branowska, D. Tetrahedron, 2004, 60, 6021. 
21. Perrin D.D.; Armarego W.L. F. Purification of Laboratory Chemicals; Pergamon: Oxford, U.K. 1992.

22. Neunhoeffer, H.; Henning, H.-W.; Frühauf, M.; Mutterer, M. Tetrahedron Lett. 1969, 3147.

23. Kuehne, M. E. J. Am. Chem. Soc. 1959, 81, 5400.

Sample Availability: Available from the author.

(C) 2005 by MDPI (http://www.mdpi.org). Reproduction is permitted for noncommercial purposes. 